\title{
Turning waste heat into water: a new desalination process
}

\author{
E. Martinson, B. Moore \& D. Raviv \\ Department of Electrical Engineering, Florida Atlantic University, USA
}

\begin{abstract}
As growing populations place stress on limited water resources, new technologies are needed to solve problems of water supply, ensuring human well-being and environmental protection. To that end, this study investigates a new method of water distillation for purposes of desalination or purification with significant advantages over existing techniques. This process uses barometric pressure to support columns of water ten meters high, efficiently maintaining near-vacuum conditions in the space above the water surface.

Sub-atmospheric pressure decreases the boiling point of the water in the columns, making practical the use of lower-temperature heat sources like the waste heat discharged from power plants, water heated by solar-thermal panels, or the temperature gradient found in deep ocean water. As thermal power cycles are usually only $50 \%$ efficient, using this method to provide co-generation of electricity and potable water is especially effective.

An experimental apparatus has been built and tested; results are presented demonstrating that water can be distilled under a range of conditions and using a temperature difference as small as $5{ }^{\circ} \mathrm{C}$ over ambient. Analysis of the collected data was conducted showing that this method requires less operating power than leading desalination methods.

Keywords: desalination, barometric distillation, power plant waste heat, aquifer replenishment.
\end{abstract}

\section{Introduction}

Earth's supply of fresh water is one of the most fundamental limits to the growth of human civilization and prosperity. Over one billion people around the world are already without adequate drinking water. Most of them live in developing nations, where population growth is placing even greater stress on scarce 
resources. Worldwide, water use has tripled since 1950 and $40 \%$ more fresh water will be needed to meet our needs in 20 years. Unfortunately, only $2.5 \%$ of earth's water is fresh, and of that only $1 \%$ is liquid and accessible [1].

Sea water is, of course, plentiful; moreover, the fastest growth in world population is projected to occur within 120 miles of a coastline, where over half the world's population already lives [2]. Here increasing demand coincides with limitless potential, suggesting that desalination technology will become a major contributor to water supply. This study investigates an alternative approach to desalination. It is a low-cost system operating at low temperature and subatmospheric pressure that can produce water at many different scales, for large cities or remote rural communities, for the First World or the Third. The system may be configured to use waste heat from power plants, making additional use of already employed resources. It is simple to operate and maintain and can be constructed from low-cost "off-the-shelf" components.

\section{Process description}

Desalinating water by distillation is nothing new. Unfortunately, previous distillation processes have been energy intensive as it is necessary to supply enough heat to raise the temperature of water to its boiling point as well as supply the latent heat of vaporization (2260 kilojoules per kilogram of water at $100^{\circ} \mathrm{C}$ ). Worse, the heat supplied must come from a source higher in temperature than the boiling point, ruling out the use of many low-temperature sources of heat.

However, the boiling point of water is dependent on pressure; at atmospheric pressure that temperature is $100{ }^{\circ} \mathrm{C}$, but in a vacuum, water boils at room temperature. This project achieves low pressure at low energy cost by applying the discovery of Evangelista Torricelli that lead to the invention of the barometer.

Torricelli observed that atmospheric pressure will support a column of water approximately 10 meters high inside a sealed tube. This proved the existence of vacuum, specifically in the space above the water level in the tube. That vacuum will cause some of the water to evaporate, the top of the tube will fill with water vapor, and the pressure will rise until it reaches the vapor pressure corresponding to the temperature of the water.

The distillation process described here uses as evaporator and condenser two of these "Torricelli Columns". The condenser is filled with fresh, pure water and the evaporator is filled with salt water or any other water to be distilled. Water in the evaporator must be at least a few degrees warmer than water in the condenser. Since the pressure at the top of both columns is low, water in the evaporator vaporizes first, raising the pressure. The resulting pressure difference between evaporator and condenser causes vapor to flow through a pipe to the condenser where it contacts cold water and becomes liquid. However, in changing phase the vapor transfers heat; removing the heat of vaporization from the evaporator and rejecting the same amount of heat to the condenser, so eventually the process will reach thermal equilibrium and distillation will cease. 
In this process, the problem of maintaining a temperature difference is solved by pumping large amounts of hot salt water into the evaporator and cold fresh water into the condenser. For example, vaporizing a single gram of water requires 2400 joules per gram (in the temperature range of interest) and 4.2 joules can change the temperature of 1 gram of water by $1{ }^{\circ} \mathrm{C}$. So if 100 grams is pumped in for each gram vaporized, the output evaporator temperature will be 5.7 degrees cooler than the input. The reverse is true for the condenser: water will exit 5.7 degrees hotter.

Figure 1 illustrates the system producing 1 gram of water per second, but the unit could be anything - 1 gram, 1 liter, 1000 gallons, provided that 100 times the desired production rate is pumped into the chambers. The 100:1 ratio is used here by example; in an operating system the actual ratio is determined by the geometry of the apparatus, the nature of the hot and cold water flows, and most importantly, by the difference in temperature between evaporator and condenser. Nonetheless, experiments have revealed that 100:1 is a realistic choice.

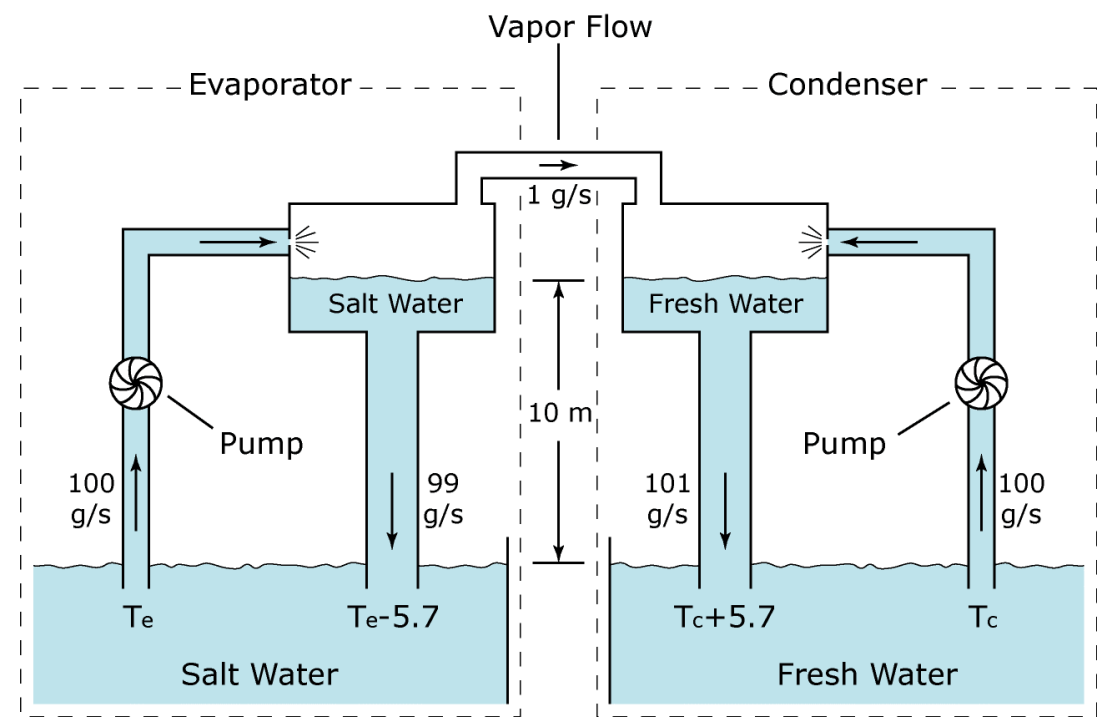

Figure 1: Distillation Process. $T_{e}=$ incoming evaporator water temperature; $\mathrm{T}_{\mathrm{c}}=$ incoming condenser water temperature.

Note the 5.7 degree change in temperature as water passes through the chambers. In practice the sources of hot salt water and cold fresh water will have to be large enough to keep our system from changing their temperatures $\left(T_{e}\right.$ and $\mathrm{T}_{\mathrm{c}}$ ) significantly; for example, the ocean and a freshwater aquifer are obvious choices. The experiments presented here have used as reservoirs two standard 55 gallon drums, which are too small to keep the process operating continuously.

Perhaps the most significant source of a useable temperature difference is the waste heat rejected by power plants. The efficiency of any thermal power plant is limited by the Carnot efficiency, a consequence of the second law of 
thermodynamics. Real power plants are about 50-60\% efficient, so for every megawatt of electrical capacity, roughly one megawatt of excess heat is rejected into the atmosphere or a nearby body of water. This distillation process can put that presently wasted heat to additional use, producing some fresh water at lower cost than competing methods.

\section{Experimental apparatus}

A small-scale implementation of this process (Figure 2) was constructed and tested by the authors. It is a "low-tech" machine constructed mostly from common plumbing components and installed in a university building between the fourth and second floors to obtain the 10 meter height necessary for the barometric columns.

The idea of using barometric columns as a source of low pressure for desalination purposes has existed since at least as long ago as 1949. Several patents have been issued on similar processes since then. However, recent experiments have revealed that certain innovations introduced by the authors, and related to the manner of injecting water into evaporator and condenser, are necessary to make such a system functional.

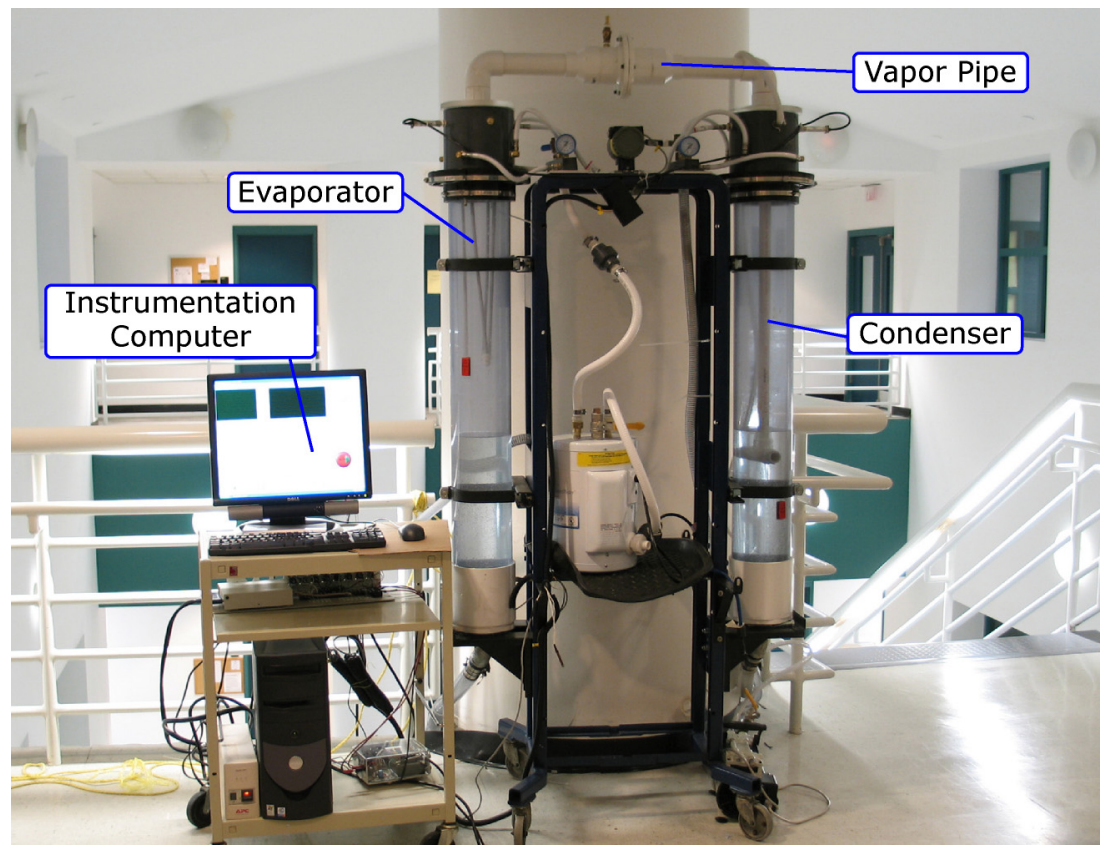

Figure 2: Experimental Apparatus. Evaporator and condenser are on the fourth floor, 10 meters above the tanks on the second floor. 


\section{Results}

To begin a distillation experiment, water in the evaporator tank is circulated through a heating loop for a period of approximately two hours, until it reaches a constant temperature of $51.5{ }^{\circ} \mathrm{C}$ - the limit of this particular combination of heaters and apparatus. At this point, the valve separating evaporator from condenser is opened and distillation begins. Water on the evaporator side continues to circulate through the water heaters, which add $3 \mathrm{~kW}$ of heat to the system; this additional heat allows the experiment to continue for a longer time.

The results shown in Figure 3 are typical. Observe the convergence of temperatures; the evaporator slope is less extreme due to the influence of the heaters. The temperatures change almost entirely due to phase change, as tested by a control experiment. The presented experimental apparatus does not permit continuous operation due to the small hot and cold reservoirs employed and the undersized heat sources; this system will produce water for 40-50 minutes, until the temperature difference between evaporator and condenser becomes too small for distillation to continue.

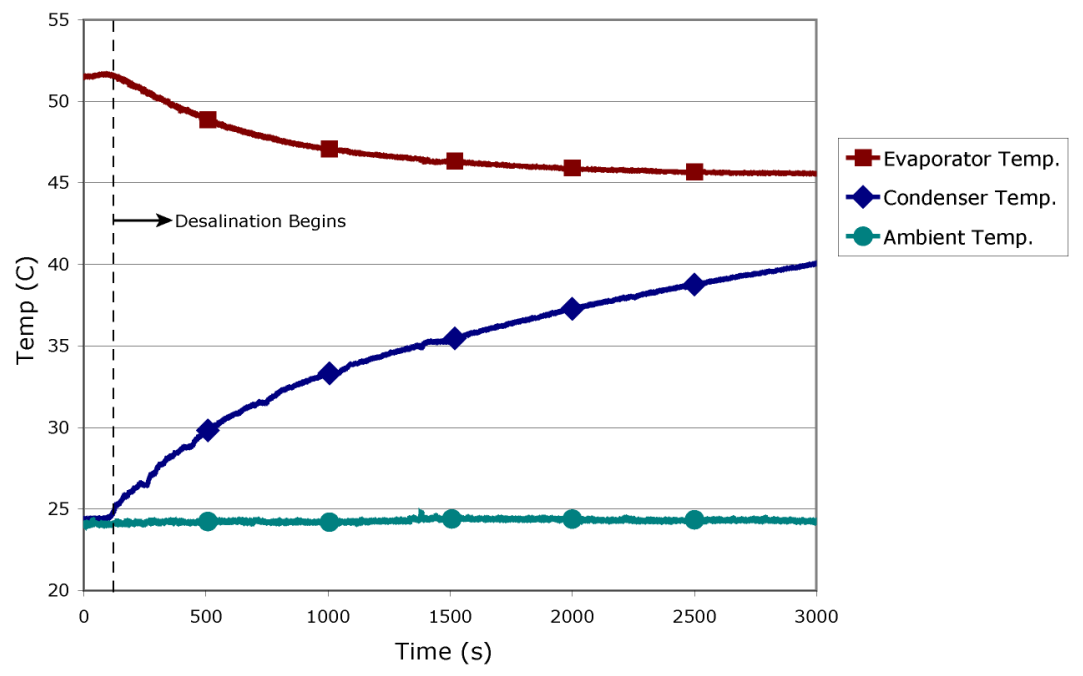

Figure 3: Desalinator temperature performance.

Since each gram of vapor releases approximately 2400 joules in condensing, and 4.2 joules will raise the temperature of 1 gram by $1{ }^{\circ} \mathrm{C}$, it is possible to predict the distillation rate from the temperature change in the condenser:

$$
\Delta V=\Delta T_{C} V_{0} \frac{4.2 \mathrm{~J} /{ }^{\circ} \mathrm{C}}{2400 \mathrm{~J}}
$$


where $\Delta T_{C}$ is the final change in temperature of the condenser, $V_{0}$ is the initial volume in liters (in this case, 150 l) of water in the condenser reservoir, and $\Delta V$ is the change in that volume (in liters), or the amount of water produced by the system.

In the case of the data shown above:

$$
\Delta V=\left(15.69^{\circ} \mathrm{C}\right)(150 \text { liters }) \frac{4.2 \mathrm{~J} /{ }^{\circ} \mathrm{C}}{2400 \mathrm{~J}}=4.1 \text { Liters }
$$

The system has produced 4.1 liters of fresh water during the experiment. This result has been experimentally confirmed by measuring the water level before and after distillation.

From the plot in figure 3 one can see that the production rate of the system declines as the temperature difference between columns decreases; most of the product water was made in the first half of the experiment, when a large temperature difference was available. Using a similar analysis as above, it is possible to use the data from figure 3 to plot the production rate vs. temperature difference, as in figure 4. Here the performance of the system is extended to the continuous case, as though a production system was operating using power plant waste heat and rejecting that heat into a large body of fresh water. As expected, the production rate increases exponentially with temperature difference. It should be noted that this projection applies only to the current apparatus - a large-scale plant would provide proportionally more water.

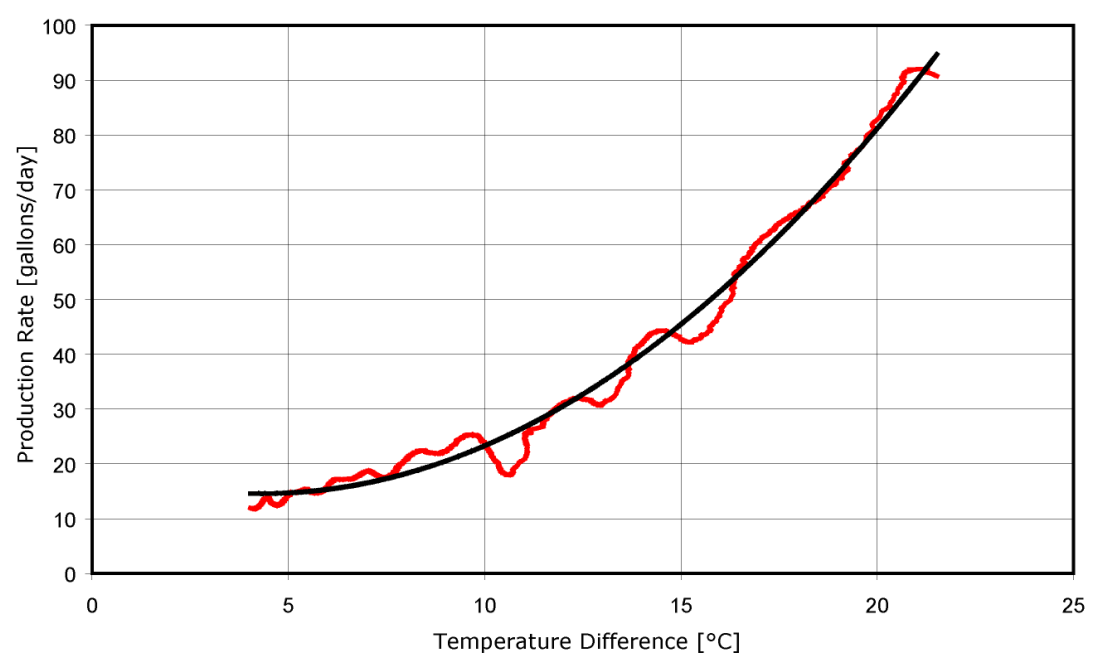

Figure 4: $\quad$ Projected daily water production. 


\section{Impact on sustainability}

Practical implementations of the process would operate in one of the following modes:

1) Heat provided to evaporator from external source, large cold reservoir: In the absence of a very large reservoir of warmer water, heat can be added to the evaporator supply from many potential sources. Power plant or industrial process waste heat would be ideal, particularly in coastal areas where ocean water is often used to cool thermal power cycles. Solar heat provided from an array of solar-thermal panels is another alternative. In any case, to maintain the temperature of the evaporator, the heat added must replace the heat lost to vaporization.

However, the condenser must also be maintained at a constant temperature if the process is to operate continuously. This can be achieved if the source of cool fresh water supplied to the condenser is so large that its temperature is not changed by the heat of condensation.

One example of this operating mode would distill hot seawater from a coastal power plant onto cold fresh water drawn from an aquifer; the cooling water would be re-injected into the aquifer with the addition of the distillate. Such an arrangement could be used to replenish stressed or overdrawn groundwater supplies. Alternatively, the hotter water provided from active heat sources like power plants or solar heating could be used to replenish relatively warm surface water, such as in a lake or reservoir.

2) Two large temperature reservoirs: For instance, the device could be operated using the temperature difference between warm surface water in the ocean and cold fresh ground water.

3) Heat provided to evaporator, heat removed from condenser: A large supply of cold fresh water may not always be available, or it may be undesirable for ecological reasons to locally warm such a body of water. In this case, it will be necessary to cool the condenser supply by some other means. A cooling tower of some type could be used to remove the heat of condensation from the recirculating fresh water supply, and produced water could be supplied to some distribution network at lower temperature. Of course, water will be lost to the atmosphere from an evaporative cooling device, but this water can be of any quality; some types of cooling tower can even be reliably cooled by the same seawater which is to be desalinated.

\subsection{Energy analysis}

Although the heat of vaporization may be considered free in many practical operating modes, some energy will be consumed by the pumps; since they are pumping many times more volume than the produced distillate, this cost can be significant. A simple analysis can predict the total amount of energy required per 
unit volume of water distilled. This pumping cost calculation assumes an additional 3 meters of head loss, due mostly to pipe friction and the resistance imposed by the spray nozzles, and the use of commercially available pumps of $85 \%$ efficiency:

$$
E=\frac{2 k}{\eta}(\rho g h) \frac{1 \mathrm{~kW} \cdot \mathrm{H}}{3.6 \times 10^{6} \mathrm{~J}}
$$

$E$ : Energy consumed per unit volume $\left[\mathrm{kW} \cdot \mathrm{H} / \mathrm{m}^{3}\right]$

$k$ : Pumping ratio

$\eta$ : Pump efficiency

$\rho:$ Density of water $\left(1026 \mathrm{~kg} / \mathrm{m}^{3}\right)$

$g$ : Acceleration due to gravity $\left(9.8 \mathrm{~m} / \mathrm{s}^{2}\right)$

$h$ : Head loss [m]

For the assumed parameters, eq. 3 yields an energy cost of $1.97 \mathrm{~kW} \cdot \mathrm{H} / \mathrm{m}^{3}$. This can be compared against the electricity cost of commercial Reverse Osmosis processes operating on seawater: $3.5 \mathrm{~kW} \cdot \mathrm{H} / \mathrm{m}^{3}$ [4]. The system presented here is more efficient by over $40 \%$, indicating that there is considerable room for such a process in the desalination field, especially if pumping ratios can be lowered below 100. Ongoing research is aimed at achieving this goal and others necessary for bringing this process to practical realization.

\section{References}

[1] Key Facts About Water; United Nations Environment Programme, http://www.unep.org/wed/2003/keyfacts.htm

[2] Hinrichsen, D., The coastal population explosion. Trends and Future Challenges for U.S. National Ocean and Coastal Policy. U.S. National Oceanic and Atmospheric Administration, 1999.

[3] Taub, M. The world's largest SWRO desalination plant. Proc. of Innovations and Applications of Sea-Water and Marginal Water Desalination: $8^{\text {th }}$ Annual Conf. R. Semiat \& D. Hasson, Israel Desalination Society: Haifa, 2006. 